Revta brasil. Bot., São Paulo, V.24, n.2, p.213-226, jun. 2001

\title{
Composição florística e estrutura do componente epifítico vascular em floresta da planície litorânea na Ilha do Mel, Paraná, Brasil
}

\author{
RODRIGO DE ANDRADE KERSTEN ${ }^{1}$ e SANDRO MENEZES SILVA ${ }^{1,2}$
}

(recebido: 21 de junho de 2000; aceito: 21 de março de 2001)

\begin{abstract}
Floristic composition and structure of the vascular epiphyte component of the coastal plain forest of "Ilha do Mel", Paraná, Brazil). This study was carried out in a $3,000 \mathrm{~m}^{2}$ area of coastal plain forest at "Ilha do Mel” ( $\left(25^{\circ} 30^{\prime} \mathrm{S} ; 48^{\circ} 23^{\prime} \mathrm{W}\right)$. The qualitative survey was carried out on the whole area, while the quantitative survey was done on 100 assorted trees, separated into two meters-high strata starting from the ground level. In each strata we recorded all of the occurring epiphytic species. The epiphytic importance index was calculated from the frequencies found for each stratum, for each host tree and for each species of host tree. In this survey, 77 species (16 of Pteridophyta, 53 of Liliopsida and 8 of Magnoliopsida) were found, of which 70 were sampled in the trees surveyed. The richest families were Orchidaceae, Bromeliaceae and Polypodiaceae, while Vriesea, Encyclia and Maxillaria were the richest genera. The area located in the Torres County (RS) presented the closest floristic similarity to the one used in this survey. From the quantitative point of view, Microgramma vaccinifolia, Codonanthe gracilis, Epidendrum latilabre and E. rigidum were the most important species. The sampled species were grouped into three categories, exclusive, preferential or indifferent, according to their occurrence in the different height intervals in relation to the ground. The frequency of epiphytic individuals in a host tree varied from 1 to 35 , while the number of species varied from 1 to 21 (average of $14 \pm 7.6$ and $10 \pm 4.6$, respectively). The first (0-2, 2-4 and 4-6 m) strata were the richest in epiphytic species. For the host tree species, the highest frequencies of epiphytic individuals were found for Andira fraxinifolia and Ternstroemia brasiliensis, while Ocotea pulchella and Guapira opposita presented the largest number of species. Regarding to fidelity on host tree species, exclusive, preferential and generalist species were found, the last one included most of the species.
\end{abstract}

RESUMO - (Composição florística e estrutura do componente epifítico vascular em floresta da planície litorânea na Ilha do Mel, Paraná, Brasil). O estudo das epífitas vasculares foi realizado em uma área de $3.000 \mathrm{~m}^{2}$ de floresta na planície litorânea na Ilha do $\operatorname{Mel}\left(25^{\circ} 30^{\prime} \mathrm{S}\right.$ $48^{\circ} 23^{\prime} \mathrm{W}$ ); o levantamento qualitativo foi realizado em toda a área; para o estudo quantitativo, foram sorteados 100 forófitos, divididos em intervalos de $2 \mathrm{~m}$ a partir do solo. Em cada intervalo, registraram-se todas as espécies epifíticas ocorrentes, sendo estimado o valor de importância epifítico a partir das frequiências nos estratos, nos forófitos e nas espécies forofíticas. No levantamento total, foram encontradas 77 espécies (16 de Pteridophyta, 53 de Liliopsida e 8 de Magnoliopsida), das quais 70 foram amostradas nos forófitos analisados. As famílias mais ricas foram Orchidaceae, Bromeliaceae e Polypodiaceae e os gêneros foram Vriesea, Encyclia e Maxillaria. A área com maior similaridade florística com este estudo localiza-se no Município de Torres (RS). As espécies mais importantes quantitativamente foram Microgramma vaccinifolia, Codonanthe gracilis, Epidendrum latilabre e E. rigidum. As espécies amostradas foram agrupadas em três categorias quanto à preferência por intervalos de altura: exclusivas, preferenciais e indiferentes. O número de ocorrências de epífitos em um mesmo forófito variou de 1 a 35, enquanto o número de espécies variou de 1 a 21 (médias $14 \pm 7,6$ e $10 \pm 4,6$, respectivamente). Os primeiros estratos (0-2 m, 2-4 m e 4-6 m) foram os mais ricos em espécies epifíticas. As espécies forofíticas com maior número de ocorrências foram Andira fraxinifolia e Ternstroemia brasiliensis, e com maior número de espécies Ocotea pulchella e Guapira opposita. Quanto à fidelidade sobre espécies forofíticas, foram encontradas espécies epifíticas exclusivas, preferenciais e generalistas, esta incluindo a maioria das espécies amostradas.

Key words - Coastal plain forests, floristic composition, vascular epiphytes, vertical distribution, restinga

\section{Introdução}

O epifitismo é responsável por parte significativa da diversidade que faz das florestas tropicais úmidas um dos mais complexos ecossistemas da Biosfera, constituindo até 50\% do total de espécies vasculares. A capacidade destas florestas em sustentar grande número de animais

1. Universidade Federal do Paraná, Setor de Ciências Biológicas, Departamento de Botânica, Caixa Postal 19031, 81531-990 Curitiba, PR, Brasil.

2. Autor para correspondência: menezes@bio.ufpr.br pode ser atribuída ao substrato e sustento provido pelas epífitas, e por sua respectiva capacidade de retenção de nutrientes de chuva, neblina e partículas em suspensão (Nadkarni 1986). A biomassa, a taxa de fotossíntese e de captação de íons podem chegar a se igualar à dos forófitos em uma mesma floresta (Benzing 1990).

As epífitas distribuem-se de forma irregular ao longo dos forófitos, apresentando variação vertical, tanto no número de indivíduos como de espécies encontradas (Steege \& Cornelissen 1989, Brown 1990, Waechter 1992, 1998). Alguns fatores que podem influenciar nos padrões de distribuição e abundância de epífitas vasculares nas florestas 
tropicais relacionam-se às variações de luminosidade e umidade estabelecidas entre o dossel e o solo, à concentração de $\mathrm{CO}_{2}$ proveniente tanto da respiração animal como da atividade fotossintética, e à arquitetura, porte e características da casca externa dos forófitos, entre outros (Lüttge 1989, Steege \& Cornelissen 1989).

A maior parte dos estudos sobre a composição florística e/ou estrutura das epífitas vasculares nas florestas do Brasil foi realizada nas regiões sul e sudeste. Na região de ocorrência da floresta ombrófila mista ("floresta com Araucaria") destacam-se os levantamentos qualitativos executados por Cervi \& Dombrowski (1985), Cervi et al. (1988) e Dittrich et al. (1999), todos na região urbana de Curitiba (PR). Em formações associadas à floresta ombrófila densa ("floresta Atlântica") podem ser mencionados os trabalhos de Waechter (1986, 1992, 1998) na planície costeira do Rio Grande do Sul, e de Labiak \& Prado (1998) em Santa Catarina. Em São Paulo, ainda nesta formação, é encontrado o estudo de Fischer \& Araújo (1995) e, no Rio de Janeiro, o de Fontoura et al. (1997). Podem ser mencionados, ainda, os estudos realizados em floresta estacional por Aguiar et al. (1981) no Rio Grande do Sul, por Dislich \& Mantovani (1998) na cidade de São Paulo e por Pinto et al. (1995) no interior paulista.

No plano de manejo da Estação Ecológica da Ilha do Mel, Paraná (SEMA/IAP 1996) foram relacionadas, de forma preliminar, 95 espécies de epífitas vasculares, distribuídas entre as diferentes tipologias vegetacionais, número considerado baixo se forem consideradas a extensão e a diversidade de ambientes da Ilha.

O presente estudo teve como objetivo principal caracterizar florística e estruturalmente o componente epifítico vascular de uma área de floresta não inundável na planície litorânea da Ilha do Mel, comumente denominada de "mata de restinga", procurando avaliar as espécies mais abundantes, a distribuição vertical das espécies amostradas e possíveis relações de ocorrência entre espécies epifíticas e seus respectivos forófitos.

\section{Material e métodos}

Área de estudo - A Ilha do Mel localiza-se na entrada da baia de Paranaguá (PR), com área aproximada de 2760 ha e perímetro de $35 \mathrm{~km}$; a área amostrada situa-se na Estação Ecológica da Ilha do Mel (EEIM), entre as coordenadas $25^{\circ} 31^{\prime} 672 \mathrm{~S}$ e $48^{\circ} 18^{\prime} 739 \mathrm{~W}$. A Ilha é composta por duas áreas bem delimitadas em relação a geologia e geomorfologia, ligadas por uma estreita faixa arenosa. A área sul, menor, é formada basicamente por morros do complexo cristalino, de idade pré-cambriana, intercalados por pequenas planícies arenosas quaternárias. A área norte é uma planície sedimentar quaternária de grande extensão, originada principalmente de depósitos marinhos, com um pequeno morro de 80 m de altura (Silva et al. 1994).

A região de Paranaguá é enquadrada na classificação de Köppen no tipo climático Af, tropical, superúmido, sem estação seca e isento de geadas (IAPAR 1978), com temperatura média anual de $21,1{ }^{\circ} \mathrm{C}$, precipitação média anual de $1960 \mathrm{~mm}$ e umidade relativa do ar com média de $85 \%$ (Silva et al. 1994).

A cobertura vegetal da Ilha do Mel é representada, conforme o sistema de classificação da vegetação brasileira de Veloso et al. (1991), pelas formações pioneiras com influência marinha ("restinga"), com influência fluviomarinha ("manguezal") e com influência fluvial ("brejos e caxetais"), além da floresta ombrófila densa, representada pelas formações de terras baixas e submontanas, e de áreas com vegetação secundária em diferentes estádios de regeneração (SEMA/IAP 1996).

O solo na área estudada foi classificado por Britez et al. (1997) como Podzol distrófico e álico a fraco ou moderado textura arenosa fase floresta não hidrófila de restinga com relevo plano. Segundo este estudo, a profundidade do lençol freático tem papel determinante na disponibilidade de nutrientes para a vegetação, caracterizada como uma floresta fechada não inundável, que tem como espécies dominantes no estrato superior Ocotea pulchella (Lauraceae), Ternstroemia brasiliensis (Theaceae), Ilex pseudobuxus (Aquifoliaceae), Clusia criuva e Calophyllum brasiliense (Clusiaceae). A densidade total de indivíduos arbustivo-arbóreos estimada na área foi de 2.783,3 indiv.ha ${ }^{-1}$, a área basal total de $23,97 \mathrm{~m}^{2} \cdot \mathrm{ha}^{-1}$, o índice de Shannon $\left(\mathrm{H}^{\prime}\right) \mathrm{de}$ 2,495 e a eqüidade (J) de 0,766 . Foram amostradas 26 espécies nesse estrato, distribuídas em 15 famílias, com destaque em riqueza específica para Myrtaceae, representada por oito espécies (S.M. Silva, dados não publicados).

Procedimento metodológico - O levantamento das epífitas vasculares foi realizado em uma área de $3000 \mathrm{~m}^{2} \mathrm{em}$ floresta não inundável na planície costeira da Ilha do Mel, dividida em 30 parcelas de $100 \mathrm{~m}^{2}$. Para o estudo qualitativo, foram realizadas diversas excursões pela área, sendo coletadas todas as espécies observadas. Para o estudo quantitativo, foram sorteadas em campo entre 3 e 5 árvores em cada parcela, com no mínimo $30 \mathrm{~cm}$ de perímetro a 1,3 m de altura do solo, totalizando 100 indivíduos, que foram identificados em campo com base em levantamento anterior já realizado na área (S.M. Silva, dados não publicados). Foi utilizado o sistema proposto por Waechter (1992) de divisão vertical do forófito em intervalos de $2 \mathrm{~m}$, a partir da superfície do solo, denominados por este autor como "estratos", nos quais foram registradas todas as espécies epifíticas ocorrentes. No presente estudo, o termo estrato foi adotado com o mesmo sentido. Indivíduos epifíticos muito jovens, cuja identificação em campo ou através de material coletado é praticamente impossível, não 
foram considerados nesta amostragem, e tampouco no estudo florístico.

O material foi coletado e herborizado conforme os procedimentos usuais em trabalhos de levantamento florístico, e foi tombado no Herbário do Departamento de Botânica da Universidade Federal do Paraná (UPCB). Espécies não reconhecidas em campo foram coletadas quando férteis ou identificadas como morfoespécies, até que fosse possível sua coleta e determinação específica. Os nomes das espécies foram verificados no Index Kewensis (1993), sendo utilizadas as abreviaturas dos autores sugeridas por Brummitt \& Powell (1992). As espécies levantadas foram classificadas em cinco categorias ecológicas, de acordo com sua relação com o forófito (Benzing 1990) a saber: holoepífito característico: normalmente nascem e crescem sobre outros vegetais; holoepífito facultativo: em uma mesma comunidade, podem crescer tanto como epífitos quanto como terrícolas; holoepífito acidental: geralmente terrícolas, mas casualmente podem desenvolver-se como epífitos; hemiepífito primário: nascem sobre outros vegetais e, posteriormente, estabelecem contato com o solo; hemiepífito secundário: germinam no solo e, ao estabelecerem contato com um forófito, degeneram a porção basal do sistema radicial/caulinar.

As fórmulas empregadas para estimativa das frequiências absoluta e relativa sobre os forófitos (FAi e FRi), e sobre as espécies forofíticas (FAj e FRj), basearam-se em Waechter (1998). As freqüências absoluta e relativa nos intervalos de altura amostrados (FAe e FRe) foram obtidas com base nas seguintes fórmulas: $\mathrm{FAe}=\left(\mathrm{ne} \cdot \mathrm{na}^{-1}\right) \cdot 100 ; \mathrm{FRe}=\left[\mathrm{ne} \cdot(\Sigma \mathrm{ne})^{-1}\right] \cdot 100$, onde ne $=$ número de estratos com ocorrência da espécie epifítica; na $=$ número total de estratos amostrados. No cálculo do valor de importância epifítica (VIE), foi utilizada a média aritmética das três freqüências relativas estimadas. A partir dos dados de ocorrência das espécies sobre os indivíduos forofíticos, foi calculado o índice de diversidade de Shannon (H'), também com base em Waechter (1998).

As espécies epifíticas foram classificadas a partir das ocorrências nas espécies forofíticas em três grupos de fidelidade: exclusivas, quando ocorriam somente em uma espécie de forófito, preferenciais, quando ocorriam com maior frequiência em uma ou poucas espécies, mas eventualmente encontradas em mais espécies forofíticas, e indiferentes, quando ocorriam com valores de freqüência semelhantes em diversas espécies de forófitos.

\section{Resultados}

No levantamento florístico da área de $3.000 \mathrm{~m}^{2}$, foram registradas 77 espécies de epífitas vasculares, distribuídas em 44 gêneros e 17 famílias; as pteridófitas contribuíram com sete famílias, 12 gêneros e 17 espécies, enquanto entre as magnoliófitas (60 espécies), 10 famílias foram encontradas, sendo somente três de Liliopsida (25 gêneros e 52 espécies) e sete de Magnoliopsida (sete gêneros e oito espécies). Em termos de riqueza florística, destacaram-se Orchidaceae (35 espécies e 20 gêneros ou $45 \%$ e $45 \%$, respectivamente),
Bromeliaceae (16 espécies e quatro gêneros ou $21 \%$ e $9 \%$, respectivamente) e Polypodiaceae (oito espécies e cinco gêneros ou $10 \%$ e $11 \%$, respectivamente). Com exceção destas três famílias e mais Gesneriaceae, Lomariopsidaceae, Lycopodiaceae e Vittariaceae (duas espécies cada), todas as demais (10 famílias) foram representadas por apenas uma espécie (tabela 1).

Vriesea (Bromeliaceae) foi o gênero mais rico, com 11 espécies, seguido por Encyclia e Maxillaria (Orchidaceae), ambos com cinco espécies cada, Epidendrum (Orchidaceae), com quatro espécies, Pleurothallis (Orchidaceae), Octomeria (Orchidaceae), Tillandsia (Bromeliaceae) e Pleopeltis (Polypodiaceae), representados por três espécies cada, além de quatro gêneros representados por duas espécies (Huperzia - Lycopodiaceae, Elaphoglossum - Lomariopsidaceae, Codonanthe Gesneriaceae e Polypodium - Polypodiaceae); os 32 gêneros restantes apresentaram apenas uma espécie.

A distribuição das espécies epifíticas registradas na área, de acordo com as categorias ecológicas de relação com o forófito (tabela 1), evidenciou o predomínio de holoepífitas características (54 espécies ou 70\%), dentre as quais destacaram-se as espécies de Orchidaceae, da qual somente uma espécie (Vanilla chamissonis) não foi enquadrada nesta categoria. As holoepífitas facultativas foram representadas por 14 espécies $(18 \%)$, das quais sete pertencem a Bromeliaceae. As hemiepífitas totalizaram cinco espécies (6\%), sendo ainda outras quatro espécies $(5 \%)$ classificadas como acidentais, isto é, normalmente são encontradas como terrícolas e ocasionalmente podem desenvolver-se como epífitos.

No estudo quantitativo, foram amostrados 394 estratos em 100 indivíduos, sendo registradas 1.493 ocorrências de epífitos vasculares, representados por 70 espécies, 40 gêneros e 16 famílias. $O$ índice de diversidade de Shannon (H') estimado para a amostra foi de 3,609 e a eqüidade (J) foi de 0,784.

Microgramma vaccinifolia (Polypodiaceae) destacou-se como a espécie mais importante, com valor de importância epifítica (VIE) equivalente a 11,08. Esta espécie ocorreu em $92 \%$ dos forófitos e $72 \%$ dos estratos amostrados, sendo a única epífita a aparecer em todas as espécies forofíticas e em todos os intervalos, apesar de não mostrar 
Tabela 1. Relação de espécies epifíticas vasculares registradas no levantamento florístico com respectivas categorias ecológicas em relação ao forófito (Benzing, 1990) - HLA: holoepífito acidental; HLC: holoepífito característico; HLF: holoepífito facultativo; HMP: hemiepífito primário; HMS: hemiepífito secundário - e números de registro do material de referência no UPCB. As famílias estão acompanhadas pelo número de espécies; espécies marcadas com asterisco $\left(^{*}\right)$ destacaram-se nos levantamentos dos estratos herbáceos das formações da planície costeira da Ilha do Mel (S.M. Silva dados não publicados).

\begin{tabular}{|c|c|c|}
\hline Família / Espécie & Categoria ecológica & $\mathrm{N}^{\mathrm{o}}$ registro \\
\hline \multicolumn{3}{|l|}{ ARACEAE } \\
\hline Anthurium sp. & HMS & -- \\
\hline \multicolumn{3}{|l|}{ ARALIACEAE } \\
\hline Dendropanax monogynum Decne. \& Planch. * & HLA & 19.730 \\
\hline \multicolumn{3}{|l|}{ BLECHNACEAE } \\
\hline Blechnum serrulatum Rich. & HLA & 23.761 \\
\hline \multicolumn{3}{|l|}{ BROMELIACEAE } \\
\hline Aechmea nudicaulis (L.) Griseb. & HLF & 30.441 \\
\hline Catopsis berteroniana (Schult. f.) Mez* & HLC & 19.765 \\
\hline Tillandsia gardnerii Lindl. * & HLC & 32.432 \\
\hline Tillandsia geminiflora Brongn. & HLC & 30.449 \\
\hline Tillandsia tenuifolia $\mathrm{L}$. & HLC & 31.877 \\
\hline Vriesea altodaserrae L.B. Sm. & HLF & 37.379 \\
\hline Vriesea atra $\mathrm{Mez}$ & HLC & 30.457 \\
\hline Vriesea carinata Wawra * & HLC & 30.450 \\
\hline Vriesea flammea L.B. Sm. & HLC & 19.761 \\
\hline Vriesea friburgensis Mez* & HLF & 19.776 \\
\hline Vriesea gigantea Gaudich. & HLC & 22.859 \\
\hline Vriesea phillipoccoburgii Wawra & HLF & 30.444 \\
\hline Vriesea platzmanii E. Morris & HLC & 31.321 \\
\hline Vriesea procera (Mart. ex Schult.) Witt. & HLF & 30.459 \\
\hline Vriesea rodigasiana $\mathrm{E}$. Morris & HLF & 30.446 \\
\hline Vriesea vagans (L.B. Sm.) L.B. Sm. & HLF & 30.445 \\
\hline \multicolumn{3}{|l|}{ CECROPIACEAE } \\
\hline Coussapoa microcarpa (Schott) Rizzini & HMP & 15.064 \\
\hline \multicolumn{3}{|l|}{ CLUSIACEAE } \\
\hline Clusia criuva Camb. & HLF & 24.837 \\
\hline \multicolumn{3}{|l|}{ DAVALLIACEAE } \\
\hline Nephrolepis biserrata (Sw.) Schott & HLA & 30.440 \\
\hline \multicolumn{3}{|l|}{ DRYOPTERIDACEAE } \\
\hline Rumohra adiantiformis (Forst.) Ching & HLA & 13.466 \\
\hline \multicolumn{3}{|l|}{ GESNERIACEAE } \\
\hline Codonanthe devosiana Lemée & HLC & 15.037 \\
\hline Codonanthe gracilis (Mart.) Hanst. & HLF & 15.038 \\
\hline \multicolumn{3}{|l|}{ LOMARIOPSIDACEAE } \\
\hline Elaphoglossum crassinerve (Kunze) T. Moore & HLF & 31.301 \\
\hline Elaphoglossum lingua (Raddi) Brack & HLF & 23.929 \\
\hline
\end{tabular}


(cont.)

Família / Espécie

Categoria ecológica

$\mathrm{N}^{\mathrm{o}}$ registro

\section{LYCOPODIACEAE}

Huperzia flexibilis (Fée) B. Øllg.

25.834

Huperzia mandiocana (Raddi) Trevis.

HLC

25.836

ORCHIDACEAE

Brassavola tuberculata Hook.

15.093

Campylocentron aromaticum Barb. Rodr.

37.384

Catasetum cernuum Rchb. f. *

25.085

Cattleya forbesii Lindl.

15.094

Dichaea pendula (Aubl.) Cogn.*

8.985

Encyclia inversa (Lindl.) Pabst

37.324

Encyclia fragrans (Sw.) Lemée

30.461

Encyclia pygmaea (Hook.) Dressler

HLC

HLC

Encyclia odoratissima (Lindl.) Schltr.

HLC

Encyclia vespa (Vell.) Dressler

Epidendrum latilabre Lindl.

HLC

30.442

Epidendrum ramosum Jacq.

37.388

Epidendrum rigidum (Lindl.) Benth.

HLC

HLC

Epidendrum strobiliferum Rchb. f.

Lankesterella ceracifolia (Barb. Rodr.) Mansf.

HLC

HLC

Jacquiniella globosa (Jacq.) Schltr.

HLC

Maxillaria brasiliensis Brieg. \& Illg

HLC

37.382

Maxillaria chlorantha Lindl.

Maxillaria marginata (Lindl.) Fenzl.

HLC

HLC

Maxillaria imbricata Barb. Rodr.

HLC

Maxillaria cf. parviflora (Poepp. \& Endl.) Garay

HLC

Octomeria gracilis Lodd.

HLC

Octomeria cf. fibrifera Schltr.

32.124

Octomeria sp.

HLC

Oncidium uniflorum Booth.

HLC

Paradisanthus micranthus (Barb. Rodr.) Schltr.

HLC

Pleurothallis matinhensis Hoehne

HLC

Pleurothallis saundersiana Rchb. $\mathrm{f}$.

HLC

Pleurothallis sp.

HLC

31.277

Polystachya concreta (Jacq.) Garay

HLC

HLC

$--$

Reichenbachanthus reflexus (Lindl.) Porto \& Brade

HLC

31.348

Scaphyglottis modesta (Rchb. f.) Schltr.

37.389

Physosiphon spiralis Lindl.

HLC

30.456

Trigonidium latifolium Lindl.

HLC

HLC

30.453

Vanilla chamissonis Klotzch

HMS/HMP 
(cont.)

\begin{tabular}{|c|c|c|}
\hline Família / Espécie & Categoria ecológica & $\mathrm{N}^{\mathrm{o}}$ registro \\
\hline \multicolumn{3}{|l|}{ PIPERACEAE } \\
\hline Peperomia glabella (Sw.) A. Dietr. & HLF & 30.447 \\
\hline \multicolumn{3}{|l|}{ POLYPODIACEAE } \\
\hline Campyloneurum nitidum (Kaulf.) C. Presl. & HLF & 37.397 \\
\hline Microgramma vacciniifolia (Langsd. \& Fisch.) Copel. & HLC & 31.308 \\
\hline Pecluma paradisiae (Langsd. \& Fisch.) M.G. Price & HLF & 31.310 \\
\hline Pleopeltis angusta Humb. \& Bonpl. ex Willd. & HLC & 23.774 \\
\hline Pleopeltis astrolepis (Liebm.) P. Fourn. & HLC & 31.885 \\
\hline Pleopeltis percussa Hook. \& Grev. & HLC & 37.391 \\
\hline Polypodium catharinae Langsd. \& Fisch. & HLC & 31.880 \\
\hline Polypodium hirsutissimum Raddi & HLC & 31.312 \\
\hline \multicolumn{3}{|l|}{ RUBIACEAE } \\
\hline Malanea forsteronioides Müll. Arg. & HMS & 32.641 \\
\hline \multicolumn{3}{|l|}{ SOLANACEAE } \\
\hline Dyssochroma longipes (Sendtn.) Miers & HMP & 31.361 \\
\hline \multicolumn{3}{|l|}{ VITTARIACEAE } \\
\hline Radiovittaria stipitata (Kuntze) E.H. Crane & HLC & \\
\hline Vittaria lineata (L.) Sm. & HLC & 31.918 \\
\hline
\end{tabular}

preferência acentuada por nenhum estrato, sua freqüência caiu significativamente nos superiores $\left(\chi^{2}=15,97 ; \mathrm{GL}=3 ; \mathrm{p}<0,05\right)$. A segunda espécie em importância, Codonanthe gracilis (Gesneriaceae), foi amostrada em $66 \%$ dos forófitos e $33 \%$ dos estratos (VIE = 6,57). Sua freqüência também diminuiu nos estratos superiores. Epidendrum latilabre (Orchidaceae), terceira espécie em importância (VIE = 5,94), ocorreu em $63 \%$ das árvores e $28 \%$ dos estratos amostrados. Ao contrário das anteriores, foi mais freqüente nos estratos 2-4 m (36\%) e 4-6 m (32\%). E. rigidum $(\mathrm{VIE}=5,11 \%)$ ocorreu em $23 \%$ dos intervalos e $56 \%$ dos forófitos, distribuindo-se verticalmente como a anterior (tabela 2).

As famílias mais importantes foram Orchidaceae, Polypodiaceae, Bromeliaceae e Gesneriaceae, que juntas compõem cerca de $91 \%$ do VIE; somente Orchidaceae é responsável por $50 \%$ do total (tabela 3). Gesneriaceae, embora representada por somente duas espécies, destacou-se principalmente em função da participação de Codonanthe gracilis na amostragem.

Quanto aos padrões de distribuição vertical das espécies no levantamento, fica evidente o decréscimo de riqueza específica em direção aos intervalos superiores de altura (figura 1). $\mathrm{O}$ teste de $\chi^{2}$ mostrou não haver diferença significativa entre os dois primeiros estratos $(0-2 \mathrm{~m}$ e $2-4 \mathrm{~m})\left(\chi^{2}=1,74\right.$; $\mathrm{GL}=1 ; \mathrm{p}<0,05)$, mas indicou que a partir do

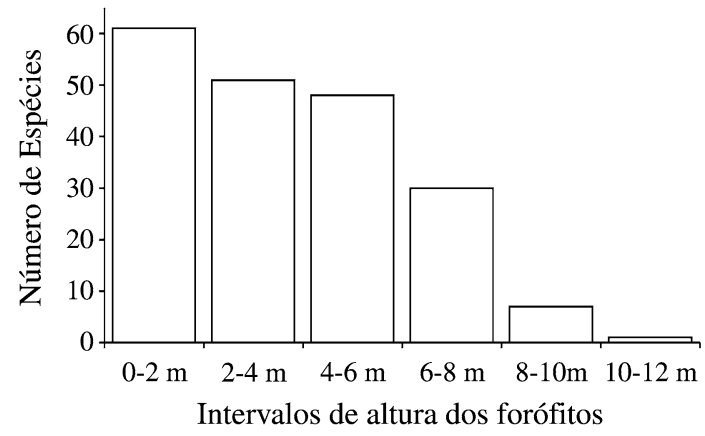

Figura 1. Número de espécies epifíticas amostradas por estrato em floresta da planície litorânea da Ilha do Mel, Paraná. 
Tabela 2. Espécies ocorrentes no levantamento quantitativo em ordem do valor de importância epifítica (ne = número de estratos com a espécie epifítica, $\mathrm{FAe}=$ frequiência absoluta nos estratos, $\mathrm{FRe}=$ freqüência relativa nos estratos, $\mathrm{FAi}=$ freqüência absoluta nos forófitos individuais, $\mathrm{FRi}=$ freqüência relativa nos forófitos individuais, $\mathrm{FAj}=$ freqüência absoluta nos forófitos específicos, $\mathrm{FSr}=\mathrm{freqüência}$ relativa nos forófitos específicos, VIE = valor de importância epifítica).

\begin{tabular}{|c|c|c|c|c|c|c|c|c|}
\hline Espécie & ne & $\mathrm{FAe}$ & FRe & FAi & FRi & $\mathrm{FAj}$ & FRj & VIE \\
\hline Microgramma vacciniifolia & 284 & 72,08 & 19,02 & 92 & 9,64 & 100 & 4,58 & 11,08 \\
\hline Codonanthe gracilis & 131 & 33,25 & 8,77 & 66 & 6,92 & 88 & 4,01 & 6,57 \\
\hline Epidendrum latilabre & 112 & 28,43 & 7,50 & 63 & 6,60 & 81 & 3,72 & 5,94 \\
\hline Epidendrum rigidum & 94 & 23,86 & 6,30 & 56 & 5,87 & 69 & 3,15 & 5,11 \\
\hline Epidendrum strobiliferum & 61 & 15,48 & 4,09 & 47 & 4,93 & 63 & 2,87 & 3,96 \\
\hline Encyclia vespa & 64 & 16,24 & 4,29 & 42 & 4,40 & 56 & 2,58 & 3,76 \\
\hline Vriesea procera & 42 & 10,66 & 2,81 & 38 & 3,98 & 69 & 3,15 & 3,32 \\
\hline Aechmea nudicaulis & 54 & 13,71 & 3,62 & 33 & 3,46 & 63 & 2,87 & 3,31 \\
\hline Scaphyglottis modesta & 41 & 10,41 & 2,75 & 29 & 3,04 & 69 & 3,15 & 2,98 \\
\hline Encyclia fragrans & 39 & 9,90 & 2,61 & 30 & 3,14 & 63 & 2,87 & 2,87 \\
\hline Polypodium catharinae & 31 & 7,87 & 2,08 & 27 & 2,83 & 44 & 2,01 & 2,30 \\
\hline Octomeria cf. fibrifera & 32 & 8,12 & 2,14 & 21 & 2,20 & 50 & 2,29 & 2,21 \\
\hline Cattleya forbesii & 18 & 4,57 & 1,21 & 15 & 1,57 & 56 & 2,58 & 1,79 \\
\hline Vriesea rodigasiana & 25 & 6,35 & 1,67 & 18 & 1,89 & 38 & 1,72 & 1,76 \\
\hline Vriesea vagans & 21 & 5,33 & 1,41 & 20 & 2,10 & 38 & 1,72 & 1,74 \\
\hline Clusia criuva & 18 & 4,57 & 1,21 & 15 & 1,57 & 50 & 2,29 & 1,69 \\
\hline Epidendrum ramosum & 23 & 5,84 & 1,54 & 16 & 1,68 & 38 & 1,72 & 1,65 \\
\hline Vriesea phillipoccoburgii & 16 & 4,06 & 1,07 & 14 & 1,47 & 50 & 2,29 & 1,61 \\
\hline Pleurothallis matinhensis & 23 & 5,84 & 1,54 & 12 & 1,26 & 31 & 2,01 & 1,60 \\
\hline Pleopeltis angusta & 16 & 4,06 & 1,07 & 15 & 1,57 & 44 & 2,01 & 1,55 \\
\hline Codonanthe devosiana & 24 & 6,09 & 1,61 & 12 & 1,26 & 38 & 1,72 & 1,53 \\
\hline Physosiphon spiralis & 18 & 4,57 & 1,21 & 13 & 1,36 & 44 & 2,01 & 1,52 \\
\hline Anthurium sp. & 13 & 3,30 & 0,87 & 13 & 1,36 & 50 & 2,29 & 1,51 \\
\hline Reichenbachanthus reflexus & 15 & 3,81 & 1,00 & 14 & 1,47 & 38 & 1,72 & 1,40 \\
\hline Octomeria gracilis & 16 & 4,06 & 1,07 & 10 & 1,05 & 38 & 1,72 & 1,28 \\
\hline Polypodium hirssutissimum & 11 & 2,79 & 0,74 & 10 & 1,05 & 44 & 2,01 & 1,26 \\
\hline Pecluma paradisiae & 9 & 2,28 & 0,60 & 9 & 0,94 & 38 & 1,72 & 1,09 \\
\hline Pleurothallis saundersiana & 12 & 3,05 & 0,80 & 7 & 0,73 & 44 & 1,43 & 0,99 \\
\hline Nephrolepis bisserata & 8 & 2,03 & 0,54 & 8 & 0,84 & 31 & 1,43 & 0,94 \\
\hline Elaphoglossum crassinerve & 9 & 2,28 & 0,60 & 9 & 0,94 & 25 & 1,15 & 0,90 \\
\hline Tillandsia geminiflora & 6 & 1,52 & 0,40 & 6 & 0,63 & 31 & 1,43 & 0,82 \\
\hline Polystachya concreta & 8 & 2,03 & 0,54 & 7 & 0,73 & 25 & 1,15 & 0,81 \\
\hline Blechnum serrulatum & 7 & 1,78 & 0,47 & 7 & 0,73 & 25 & 1,15 & 0,78 \\
\hline Oncidium uniflorum & 7 & 1,78 & 0,47 & 6 & 0,63 & 25 & 1,15 & 0,75 \\
\hline Tillandsia tenuifolia & 7 & 1,78 & 0,47 & 6 & 0,63 & 25 & 1,15 & 0,75 \\
\hline Elaphoglossum lingua & 8 & 2,03 & 0,54 & 8 & 0,84 & 19 & 0,86 & 0,74 \\
\hline Malanea fosteronioides & 6 & 1,52 & 0,40 & 5 & 0,52 & 25 & 1,15 & 0,69 \\
\hline Octomeria crassifolia & 6 & 1,52 & 0,40 & 5 & 0,52 & 25 & 1,15 & 0,69 \\
\hline Brassavola tuberculata & 4 & 1,02 & 0,27 & 4 & 0,42 & 25 & 1,15 & 0,61 \\
\hline
\end{tabular}


(cont.)

\begin{tabular}{|c|c|c|c|c|c|c|c|c|}
\hline Espécie & ne & $\mathrm{FAe}$ & $\mathrm{FRe}$ & FAi & FRi & FAj & $\mathrm{FRj}$ & VIE \\
\hline Vriesea platzmanii & 4 & 1,02 & 0,27 & 4 & 0,42 & 25 & 1,15 & 0,61 \\
\hline Peperomia glabella & 6 & 1,52 & 0,40 & 4 & 0,42 & 19 & 0,86 & 0,56 \\
\hline Pleurothallis sp. & 5 & 1,27 & 0,33 & 4 & 0,42 & 19 & 0,86 & 0,54 \\
\hline Trigonidium latifolium & 5 & 1,27 & 0,33 & 4 & 0,42 & 19 & 0,86 & 0,54 \\
\hline Huperzia mandiocana & 4 & 1,02 & 0,27 & 4 & 0,42 & 19 & 0,86 & 0,52 \\
\hline Vriesea gigantea & 4 & 1,02 & 0,27 & 4 & 0,42 & 19 & 0,86 & 0,52 \\
\hline Maxillaria brasiliensis & 4 & 1,02 & 0,27 & 3 & 0,31 & 19 & 0,86 & 0,48 \\
\hline Pleopeltis percussa & 4 & 1,02 & 0,27 & 3 & 0,31 & 19 & 0,86 & 0,48 \\
\hline Vriesea flammea & 5 & 1,27 & 0,33 & 5 & 0,52 & 13 & 0,57 & 0,48 \\
\hline Maxillaria imbricata & 4 & 1,02 & 0,27 & 4 & 0,42 & 13 & 0,57 & 0,42 \\
\hline Coussapoa microcarpa & 3 & 0,76 & 0,20 & 3 & 0,31 & 13 & 0,57 & 0,36 \\
\hline Campylocentrum aromaticum & 2 & 0,51 & 0,13 & 2 & 0,21 & 13 & 0,57 & 0,31 \\
\hline Encyclia pygmaea & 2 & 0,51 & 0,13 & 2 & 0,21 & 13 & 0,57 & 0,31 \\
\hline Jacquiniella globosa & 2 & 0,51 & 0,13 & 2 & 0,21 & 13 & 0,57 & 0,31 \\
\hline Maxillaria marginata & 3 & 0,76 & 0,20 & 3 & 0,31 & 6 & 0,29 & 0,27 \\
\hline Encyclia inversa & 3 & 0,76 & 0,20 & 2 & 0,21 & 6 & 0,29 & 0,23 \\
\hline Vriesea atra & 3 & 0,76 & 0,20 & 2 & 0,21 & 6 & 0,29 & 0,23 \\
\hline Maxillaria cf. parviflora & 2 & 0,51 & 0,13 & 2 & 0,21 & 6 & 0,29 & 0,21 \\
\hline Pleopeltis astrolepis & 2 & 0,51 & 0,13 & 2 & 0,21 & 6 & 0,29 & 0,21 \\
\hline Vittaria lineata & 2 & 0,51 & 0,13 & 2 & 0,21 & 6 & 0,29 & 0,21 \\
\hline Vanilla chamissonis & 3 & 0,76 & 0,20 & 1 & 0,10 & 6 & 0,29 & 0,20 \\
\hline Campyloneurum nitidum & 1 & 0,25 & 0,07 & 1 & 0,10 & 6 & 0,29 & 0,15 \\
\hline Dyssocchroma longipes & 1 & 0,25 & 0,07 & 1 & 0,10 & 6 & 0,29 & 0,15 \\
\hline Encyclia odoratissima & 1 & 0,25 & 0,07 & 1 & 0,10 & 6 & 0,29 & 0,15 \\
\hline Huperzia flexibilis & 1 & 0,25 & 0,07 & 1 & 0,10 & 6 & 0,29 & 0,15 \\
\hline Lankesterella ceracifolia & 1 & 0,25 & 0,07 & 1 & 0,10 & 6 & 0,29 & 0,15 \\
\hline Maxillaria chlorantha & 1 & 0,25 & 0,07 & 1 & 0,10 & 6 & 0,29 & 0,15 \\
\hline Paradisanthus micranthus & 1 & 0,25 & 0,07 & 1 & 0,10 & 6 & 0,29 & 0,15 \\
\hline Radiovittaria stipitata & 1 & 0,25 & 0,07 & 1 & 0,10 & 6 & 0,29 & 0,15 \\
\hline Rumohra adiantiformis & 1 & 0,25 & 0,07 & 1 & 0,10 & 6 & 0,29 & 0,15 \\
\hline Vriesea altodasserrae & 1 & 0,25 & 0,07 & 1 & 0,10 & 6 & 0,29 & 0,15 \\
\hline Total & 1.493 & & 100,00 & & 100,00 & & 100,00 & 100,00 \\
\hline
\end{tabular}

terceiro estrato a diferença é significativa $\left(\chi^{2}=10,54 ; \mathrm{GL}=2 ; \mathrm{p}<0,05\right)$. Apesar disto, algumas mostram preferências por determinados intervalos; $56 \%$ do total de espécies (39) não foram incluídas em nenhuma categoria por terem frequiências relativamente baixas na amostragem. A figura 2 representa a distribuição por estrato das 15 espécies de maior VIE na amostragem.
Cinco espécies $(7,1 \%)$ tiveram distribuição restrita ao intervalo 0-2 m, sendo denominadas de "exclusivas": Anthurium sp., Blechnum serrulatum, Elaphoglossum crassinerve, Elaphoglossum lingua e Nephrolepis bisserata. Entre as preferenciais, enquadraram-se 26 espécies (37\%), sendo 12 (17\%) no estrato $0-2 \mathrm{~m}$, dentre as quais figuraram 
Tabela 3. Famílias registradas na amostragem de epífitas vasculares em floresta da planície litorânea da Ilha do Mel, Paraná, Brasil, com os seus respectivos valores de VIE (valor de importância epifítica).

\begin{tabular}{lr}
\hline Família & VIE \\
\hline Orchidaceae & 49,51 \\
Polypodiaceae & 18,12 \\
Bromeliaceae & 15,71 \\
Gesneriaceae & 8,10 \\
Clusiaceae & 1,69 \\
Lomariopsidaceae & 1,64 \\
Araceae & 1,51 \\
Blechnaceae & 0,78 \\
Rubiaceae & 0,69 \\
Lycopodiaceae & 0,67 \\
Piperaceae & 0,56 \\
Cecropiaceae & 0,36 \\
Vittariaceae & 0,36 \\
Solanaceae & 0,15 \\
Dryopteridaceae & 0,15 \\
\hline
\end{tabular}

Octomeria cf. fibrifera, O. crassifolia, Clusia criuva, Maxillaria imbricata, Pecluma paradisiae, Tillandsia geminiflora, Malanea forsteronioides e Vriesea phillipoccoburgii; 10 espécies (14\%) mostraram preferência pelo estrato de 2-4 m, todas holoepífitas, dentre as quais destacam-se Scaphyglottis modesta, Cattleya forbesii, Codonanthe devosiana, Encyclia vespa, Pleopeltis angusta, Polypodium catharinae, P. hirsutissimum e Vriesea vagans. Somente quatro espécies (6\%) ocorreram preferencialmente nos estratos superiores (4-6 m e 6-8 m): Vriesea procera, $V$. gigantea, $V$. rodigasiana e Encyclia pygmaea. Duas espécies (3\% do total) não apresentaram preferência marcada por algum estrato, ocorrendo em vários intervalos de diferentes forófitos, ou ao longo de todos os intervalos de um mesmo forófito, sendo consideradas "indiferentes"; são elas Microgramma vaccinifolia e Tillandsia tenuifolia.

A riqueza e frequiência dos epífitos por espécie de forófito foi variável. As espécies forofíticas que apresentaram maior média de ocorrências por indivíduo foram Andira fraxinifolia (Fabaceae), com 21 ocorrências, Ternstroemia brasiliensis

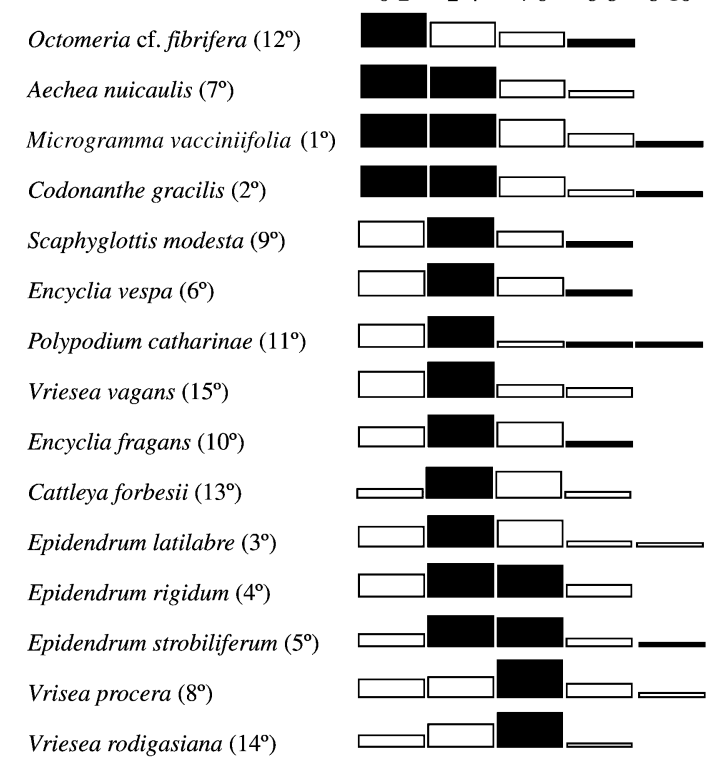

Figura 2. Distribuição das freqüências de ocorrência das 15 espécies de maior VIE (62\% do total da amostragem) nos estratos. A altura de cada barra indica a freqüência percentual de ocorrência da espécie no estrato; as barras escuras indicam a moda para cada espécie amostrada; entre parênteses, é indicada a posição da espécie segundo seu VIE; as espécies estão reunidas conforme os seus respectivos estratos preferenciais de ocorrência.

(Theaceae) com 19, Ocotea pulchella (Lauraceae) com 18 e Clusia criuva (Clusiaceae) com 18. Rapanea intermedia, $R$. venosa (Myrsinaceae), Myrcia multiflora e Psidium cattleianum (Myrtaceae) apresentaram os indivíduos forofíticos com menor número de ocorrências e de espécies epifíticas (tabela 4).

O número de epífitos em um mesmo forófito variou de uma a 35 ocorrências e de uma a 21 espécies, sendo que o número médio de ocorrências de epífitos por forófito foi $14( \pm 7,6)$ e de espécies foi $10( \pm 4,6)$. O maior número de ocorrências (35) foi observado sobre um indivíduo de Clusia criuva, e a maior riqueza (21 espécies) sobre uma árvore de Ternstroemia brasiliensis. Outras sete espécies forofíticas também apresentaram número relativamente alto de ocorrências (acima de 25), além de 18 indivíduos com ocorrência de 15 ou mais espécies epifíticas. Em dois forófitos, Calophyllum brasiliense (Clusiaceae) e Psidium cattleianum, foi observada apenas uma espécie epífita. Apesar de 
Tabela 4. Espécies forofíticas empregadas na amostragem das epífitas vasculares em floresta da planície costeira da Ilha do Mel, Paraná, com seus respectivos número de árvores amostradas $(\mathrm{N})$, média de ocorrências de epífitos (Méd. ocor.), média de espécies epifíticas (Méd. spp.), seguidas respectivamente dos desvios-padrão (S).

\begin{tabular}{lccccc}
\hline Espécie forofítica & $\mathrm{N}$ & Méd.ocor. & $\mathrm{S}$ & Méd. spp. & $\mathrm{S}$ \\
\hline Ocotea pulchella Mart. & 21 & 18 & 5,63 & 13 & 3,79 \\
Ternstroemia brasiliensis Camb. & 19 & 19 & 5,74 & 12 & 3,61 \\
Calophyllum brasiliense Camb. & 12 & 12 & 6,56 & 7 & 3,91 \\
Ilex pseudobuxus Reissek & 10 & 11 & 6,87 & 7 & 3,68 \\
Clusia criuva Camb. & 8 & 18 & 10,53 & 12 & 5,18 \\
Ilex theezans Mart. & 6 & 7 & 3,92 & 5 & 2,43 \\
Andira fraxinifolia Benth. & 5 & 21 & 3,97 & 11 & 2,41 \\
Erythroxylum amplifolium (Mart.) Schult. & 4 & 15 & 4,55 & 11 & 3,37 \\
Tapirira guianensis Aubl. & 4 & 14 & 10,87 & 9 & 4,93 \\
Myrcia multiflora (Lam.) DC. & 3 & 6 & 3,79 & 4 & 2,65 \\
Psidium cattleianum Sabine & 3 & 4 & 2,65 & 3 & 2,08 \\
Calyptranthes rubella (Berg) Legrand & 1 & 24 & - & 10 & - \\
Guapira opposita (Vell.) Reitz & 1 & 18 & - & 12 & - \\
Pouteria beaurepairei (Glaz. \& Raunk.) Baeh. & 1 & 14 & - & 8 & - \\
Rapanea intermedia Mez & 1 & 4 & - & 3 & - \\
Rapanea venosa (DC.) Mez & 1 & 6 & - & 5 & - \\
\hline
\end{tabular}

existirem na área árvores sem epífitos vasculares, nenhuma foi sorteada e incluída no levantamento quantitativo.

As maiores médias de riqueza epifítica por forófito foram obtidas para Ocotea pulchella, com 13, Clusia criuva e Ternstroemia brasiliensis, cada uma com 12, Andira fraxinifolia e Erythroxylum amplifolium (Erythroxylaceae), ambas com 11 espécies (tabela 4).

\section{Discussão}

A distribuição das espécies epifíticas nas famílias seguiu uma tendência observada em diversos trabalhos de levantamento de epífitas vasculares realizados no Brasil: poucas famílias com muitas espécies e muitas famílias representadas por uma ou poucas espécies (Waechter 1986, 1992, 1998, Fontoura et al. 1997, Dislich \& Mantovani 1998, Dittrich et al. 1999). As famílias mais ricas, Orchidaceae, Bromeliaceae e Polypodiaceae (77\% das espécies), são também os grupos de maior riqueza em outros estudos pontuais desta natureza realizados na região neotropical (Sudgen \& Robins
1979, Kelly 1985, Cervi \& Dombrowski 1985, Cervi et al. 1988, Waechter 1986, 1992, 1998, Freiberg 1996, Olmsted \& Juárez 1996, Fontoura et al. 1997, Dislich \& Mantovani 1998, Dittrich et al. 1999). Figuram, também, como as famílias mais ricas em sínteses sobre a composição taxonômica de epífitas vasculares nos trópicos (Maddison 1977, Kress 1986, Gentry \& Dodson 1987, Benzing 1990). Dentre as 11 famílias representadas por somente uma espécie, algumas foram mais ricas em outras localidades da região Neotropical, como Araceae (Fontoura et al. 1997) e Piperaceae (Nadkarni 1986).

A riqueza florística da área estudada, quando comparada com outras de planície costeira estudadas no Brasil, pode ser considerada elevada (tabela 5), sendo menor somente em relação às de Torres, no Rio Grande do Sul (Waechter 1986, 1992). Apesar destas localizarem-se aproximadamente a $400 \mathrm{~km}$ em linha reta ao sul da Ilha do Mel, nos limites do contingente florístico tropical, são florestas consideravelmente mais úmidas e de maior porte ("matas paludosas"), com maior umidade atmosférica e supostamente com maior número de nichos proporcionados pela estratificação das copas 
Tabela 5. Características de riqueza e diversidade em estudos quali-quantitativos de epífitas vasculares realizados no Brasil; Localização = coordenadas geográficas aproximadas da área estudada; Método = metodologia empregada ( 1 - levantamento qualitativo; 2 - levantamento quali-quantitativo); $\mathrm{N}^{\circ}$ for. = número de forófitos analisados; Área = extensão aproximada da área analisada (ha); H' = índice de diversidade de Shannon; SPPa = número de espécies amostradas; SPPt = número total de espécies registradas na área. (s.i. = sem informação disponível).

\begin{tabular}{|c|c|c|c|c|c|c|c|}
\hline Localidade & Localização & Método & $\mathrm{N}^{\circ}$ for. & Área & $\mathrm{H}^{\prime}$ & SPPa & SPPt \\
\hline Estação Ecológica do Taim, RS (Waechter 1992) & $32^{\circ} 33^{\prime} \mathrm{S} ; 55^{\circ} 26^{\prime} \mathrm{W}$ & 2 & 60 & s.i. & 2,886 & 24 & 24 \\
\hline Restinga de Emboaba, Osório, RS (Waechter 1998) & $29^{\circ} 58^{\prime} \mathrm{S} ; 50^{\circ} 14^{\prime} \mathrm{W}$ & 2 & 60 & 16 & 2,990 & 31 & 53 \\
\hline Montenegro / Triunfo, RS (Aguiar et al. 1981) & $29^{\circ} 50^{\prime} \mathrm{S} ; 51^{\circ} 27^{\prime} \mathrm{W}$ & 2 & 37 & s.i. & s.i. & $17 *$ & $17^{*}$ \\
\hline Torres I, RS (Waechter 1986) & $29^{\circ} 21^{\prime} \mathrm{S} ; 49^{\circ} 45^{\prime} \mathrm{W}$ & 1 & s.i. & s.i. & s.i. & s.i. & 115 \\
\hline Torres II, RS (Waechter 1992) & $29^{\circ} 21^{\prime} \mathrm{S} ; 49^{\circ} 48^{\prime} \mathrm{W}$ & 2 & 60 & s.i. & 4,049 & 93 & 93 \\
\hline Ilha do Mel, Paranaguá, PR (este estudo) & $25^{\circ} 30^{\prime} ’ \mathrm{~S} ; 48^{\circ} 23^{\prime} \mathrm{W}$ & 2 & 100 & 0,3 & 3,608 & 71 & 77 \\
\hline Parque Barigüi, Curitiba, PR (Dittrich et al. 1999) & $25^{\circ} 25^{\prime} \mathrm{S} ; 49^{\circ} 18^{\prime} \mathrm{W}$ & 1 & s.i. & 50 & s.i. & s.i. & 72 \\
\hline C.U.A.S.O, São Paulo, SP (Dislich \& Mantovani 1998) & $23^{\circ} 33^{\prime} \mathrm{S} ; 46^{\circ} 43^{\prime} \mathrm{W}$ & 1 & 86 & 0,2 & s.i. & s.i. & 38 \\
\hline
\end{tabular}

* - duas espécies hemiparasitas não foram consideradas.

dos forófitos. Em outras áreas no Rio Grande do Sul estudadas por este autor (Waechter 1992 - Taim; Waechter 1998 - Tramandai), localizadas em uma zona onde a influência tropical é consideravelmente menor, a riqueza foi menor ( 24 e 53 espécies, respectivamente), provavelmente como reflexo da distribuição geográfica eminentemente tropical da maioria dos grupos taxonômicos com representatividade no componente epifítico vascular destas florestas (Benzing 1987).

O Parque Barigüi, cuja vegetação é constituída basicamente por floresta ombrófila mista (Dittrich $e t$ al. 1999), localizado a apenas $90 \mathrm{~km}$ em linha reta da Ilha do Mel em direção ao interior do estado do Paraná, apresentou 72 espécies, valor de riqueza muito próximo ao da área estudada. Deve ser considerado que o estudo realizado neste Parque teve abordagem somente qualitativa e cobriu uma área de aproximadamente 50 ha de remanescentes florestais, enquanto a área estudada na Ilha possui somente 0,3 ha. Esta consideração faz-se necessária não só em relação ao trabalho citado, como também para os demais consultados, tendo em vista que diferentes métodos de levantamento, áreas amostrais e esforços de coleta obviamente refletem-se nos resultados obtidos. A despeito disto, algumas tendências gerais relacionadas à riqueza e diversidade do componente epifítico em florestas do sul e sudeste do Brasil podem ser claramente percebidas.
A elevada diversidade específica detectada na área estudada é consequiência, ao menos em parte, da freqüência das espécies nos indivíduos forofíticos; algumas espécies tiveram frequiências relativamente altas, mas a maioria ocorreu com baixa frequiência. As espécies que tiveram valores baixos de freqüência (inferiores a 20\%) somam cerca de $75 \%$ das espécies e $40 \%$ do VIE total da amostra, evidenciando, assim, a importância deste grupo na caracterização da comunidade como um todo. As quatro espécies que ocorreram em mais de 50\% dos forófitos analisados, são responsáveis por cerca de $30 \%$ do VIE total da amostra, podendo, portanto, ser chamadas de dominantes. Quando comparada com outras áreas onde índices analíticos foram empregados para avaliação da diversidade (tabela 5), a área da Ilha do Mel mostrou um valor relativamente alto, inferior somente ao índice obtido para a área estudada por Waechter (1992) na planície costeira de Torres (RS).

Quanto às formas de vida ocorrentes entre as espécies registradas, a predominância de espécies e indivíduos holoepífitos característicos sobre as demais categorias foi, também, observada por Dittrich et al. (1999) em uma área de floresta com Araucaria (floresta ombrófila mista) e por Waechter (1992) para áreas de planície costeira no Rio Grande do Sul. Embora o predomínio de holoepífitas características seja um traço marcante do componente epifítico na Ilha do Mel, as holoepífitas facultativas e acidentais representaram cerca de $24 \%$ 
das espécies levantadas, valor superior ao encontrado por Dittrich et al. (1999) e por Waechter (1992). Esta diferença deve-se, possivelmente, às características do solo da área estudada na Ilha do Mel, cujo horizonte L (superficial) é formado essencialmente por matéria orgânica ainda não decomposta e micélios de fungos (Britez et al. 1997), com várias características semelhantes ao substrato proporcionado pelos forófitos. A baixa altura das árvores e a inexistência de um estrato intermediário definido, permitindo índices de luminosidade relativamente maiores no interior da floresta, também podem ser fatores condicionantes importantes para o estabelecimento de epífitas diretamente sobre o solo, assim como o regime de drenagem mais rápida observado nesta área, quando comparada com outras regiões da planície costeira. Waechter (1998) também ressaltou a ocorrência de espécies epifíticas crescendo no solo e espécies terrícolas desenvolvendo-se como epífitas em uma área na planície costeira do Rio Grande do Sul, apontando as mesmas características estruturais da vegetação e do substrato como fatores condicionantes deste fato.

$\mathrm{Na}$ amostragem realizada com base nos 100 forófitos escolhidos, foram representadas cerca de $92 \%$ do total de espécies, $95 \%$ dos gêneros e $94 \%$ das famílias, em relação ao levantamento qualitativo da área como um todo, evidenciando que o método empregado para a avaliação quantitativa mostrou-se satisfatório para uma caracterização florística da comunidade epifítica.

A espécie com maior valor de importância na área, Microgramma vacciniifolia, tem ampla distribuição geográfica, ocorrendo em praticamente toda a América tropical (Sehnem 1970), denotando sua alta plasticidade e capacidade de adaptar-se a diferentes ambientes, permitindo, assim, que ocorra abundantemente nos diversos estratos da floresta e nas diferentes espécies de forófitos. Esta espécie, dotada de rizomas longo-reptantes, pode tanto ficar pendente dos galhos e, ao encostar em galhos inferiores, fixar-se e constituir um novo indivíduo, como também estabelecer-se em uma determinada altura e crescer em direção às partes mais altas do forófito. Outro fator que certamente influencia na abundância desta espécie é a grande quantidade de esporos produzidos praticamente ao longo de todo o ano, relacionada à dispersão destes pelo vento. Esta espécie foi registrada como a de maior VIE por Waechter $(1992,1998)$ em Torres e Tramandaí (RS), respectivamente, destacando-se, ainda, (segunda espécie em VIE) em levantamento realizado na região do Taim, também no Rio Grande do Sul (Waechter 1992), todas áreas de planície costeira.

A segunda espécie em importância, Codonanthe gracilis, também apresenta caules reptantes ou pendentes, podendo tanto subir pelo tronco dos forófitos, como colonizar galhos inferiores ao ponto de estabelecimento, sendo sua dispersão, diferentemente de Microgramma vacciniifolia, feita por pássaros que se alimentam de seus frutos alaranjados. Esta espécie mostrou preferência pelos estratos 0-2 m e 2-4 m, diminuindo significativamente sua freqüência nos intervalos superiores. Embora Chautems (1997) mencione como área de ocorrência desta espécie, além do Paraná, as regiões costeiras da Bahia até o Rio Grande do Sul, somente em Fontoura et al. (1997) foi mencionada como componente da flora epifítica. As três espécies seguintes em VIE (Epidendrum latilabre, E. rigidum e E. strobiliferum), juntas totalizaram cerca de $18 \%$ do VIE da amostra, todas holoepífitas características. Duas destas (E. rigidum, E. strobiliferum) têm distribuição geográfica bastante ampla, sendo citadas em levantamentos realizados na Guiana (Steege \& Cornelissen 1989), Guiana Francesa (Freiberg 1996) e na Flórida - EUA (Bennet 1986). Algumas características interessantes relativas a estas espécies, tais como a forma de crescimento (todas com ramos ascendentes), as cores de suas flores (que variam de amarelo-esverdeadas até verdes) e a preferência que apresentam pelos intervalos de altura entre 4-6 $\mathrm{m}$ e 6-8 $\mathrm{m}$, entre outras, podem implicar em alguma estratégia de partição temporal de recursos, fato que poderá ser testado em trabalhos posteriores.

A distribuição diferencial da abundância de indivíduos e da riqueza de espécies nos distintos intervalos de altura na floresta decorre de fatores como umidade, luminosidade, disponibilidade e condições do substrato (Benzing 1990). Nos estratos entre 2 e $6 \mathrm{~m}$ na floresta estudada, onde, em geral, as árvores apresentam maior número de galhos e ramificações, observa-se maior superfície para a fixação das epífitas e condições intermediárias de 
luminosidade e umidade. Nos estratos superiores, onde a incidência de luz é maior e provavelmente a umidade é menor, com maior influência dos ventos vindos do oceano, também ocorre um grande número de ramos para a fixação de epífitas, porém, em geral, estes são mais finos e novos, não permitindo o estabelecimento e desenvolvimento de muitas espécies, tanto por questões mecânicas, como espaciais e temporais. A frequiência de ocorrência e diversidade de epífitas na área estudada foram maiores nos estratos inferiores, com uma acentuada diminuição nos superiores, ao contrário do observado em outros trabalhos (Waechter 1992), em que os intervalos mais ricos foram os intermediários. Entre as 15 espécies consideradas mais importantes no levantamento quantitativo, 11 apresentaram preferência por estratos médios ou superiores de altura (figura 2). A diferença deve-se, provavelmente, ao fato da floresta estudada, conforme já afirmado anteriormente, ter bons níveis de luminosidade no seu interior, propiciando um bom desenvolvimento epifítico. Como esta floresta é menos sujeita às inundações periódicas tão características de amplos trechos da planície costeira na região, os estratos inferiores constituem importantes substratos para espécies hemiepífitas secundárias, como Anthurium sp., ou preferencialmente terrícolas, como Blechnum serrulatum.

A ocorrência de epífitas facultativas ou acidentais preferencialmente no intervalo de altura de 0-2 m indica que as condições semelhantes entre os hábitats proporcionados pelo solo e pela base dos forófitos são decisivas para o estabelecimento destas. Ao mesmo tempo, das quatro espécies de epífitas preferenciais pelos estratos superiores, três são bromélias-tanque (Vriesea gigantea, V. procera e $V$. rodigasiana), com melhores condições para captação da água de chuva, e a outra (Encyclia pygmaea) apresenta forte redução vegetativa e suculência no caule e folhas, estratégias que, segundo Benzing (1990), relacionam-se às adaptações das epífitas ao estresse hídrico ocorrente no ambiente epifítico.

A frequiência dos epífitos vasculares sobre diferentes indivíduos forofíticos está relacionada a fatores intrínsecos destes, tais como tamanho, idade, arquitetura da árvore e características da casca, ou a adaptações da própria espécie epifítica (Benzing
1990). Na área amostrada, certas espécies forofíticas possuem características que possibilitam o estabelecimento dos diásporos de epífitas, tais como Calophyllum brasiliense, que possui casca com fendas profundas, Ocotea pulchella e Ternstroemia brasiliensis, ambas com súber lenticelado e rugoso e arquitetura propícia para a fixação das epífitas, como ramos grossos e horizontais no primeiro e grande quantidade de galhos nas demais.

Apesar deste trabalho não ter o objetivo de analisar a especificidade entre epífitas e forófitos, observações realizadas em campo revelaram menores abundância e riqueza de epífitas nas espécies de Ilex (I. pseudobuxus e I. theezans Aquifoliaceae) em relação às demais espécies analisadas. Esta diferença aparentemente não está relacionada com as características dendrológicas destas espécies, pois apresentam casca relativamente rugosa e copas bastante ramificadas, podendo estar relacionadas a algum tipo de impedimento químico ao estabelecimento de epífitas, conforme sugerido por Benzing (1990).

Além destas, outras espécies como Rapanea intermedia e $R$. venosa (Myrsinaceae) também parecem ser menos atraentes às epífitas, pois mostraram ocorrências relativamente baixas de espécies, assim como Myrcia multiflora e Psidium cattleianum (Myrtaceae), estas por perderem anualmente parte da casca ("ritidoma") e dificultarem o estabelecimento das espécies epifíticas.

Agradecimentos - À Coordenação do Curso de Ciências Biológicas da Universidade Federal do Paraná, pela oportunidade de desenvolvimento deste trabalho; a Marília Borgo, pelas sugestões e correções feitas no manuscrito; ao Prof. Alexandre Uhlmann, pelo auxílio nas análises dos dados; aos colegas que auxiliaram no trabalho de campo; ao Prof. Dr. Adaucto Bellarmino de Pereira Netto, pela elaboração do abstract; ao Vinícius Antônio de O. Dittrich, pelas determinações específicas das pteridófitas; ao Instituto Ambiental do Paraná, pela autorização para execução do trabalho na Estação Ecológica da Ilha do Mel.

\section{Referências bibliográficas}

AGUIAR, L.W., CITADINI-ZANETTE, V., MARTAU, L. \& BACKES, A. 1981. Composição florística de epífitos vasculares numa área localizada nos municípios de Montenegro e Triunfo, Rio Grande do Sul, Brasil. Iheringia (Série Botânica) 28:55-93. 
BENNET, B.C. 1986. Patchness, diversity, and abundance relationships of vascular ephiphytes. Selbyana 9:70-75.

BENZING, D.H. 1987. Vascular epiphytism: taxonomic participation and adaptive diversity. Annals of the Missouri Botanical Garden 74:183-204.

BENZING, D.H. 1990. Vascular epiphytes. Cambridge University Press, Cambridge.

BRITEZ, R.M., SANTOS-FILHO, A., REISSMANN, C.B., SILVA, S.M., ATHAYDE, S.F., LIMA, R.X. \& QUADROS, R.M.B. 1997. Nutrientes do solo de duas florestas da planície litorânea da Ilha do Mel, Paranaguá, PR. Revista Brasileira de Ciência do Solo 21:625-634.

BROWN, D.A. 1990. El epifitismo en las selvas montanas del Parque Nacional "El Rey" Argentina: Composición florística y patrón de distribución. Revista de Biologia Tropical 38:155-166.

BRUMMIT, R.K. \& POWELL, C.E. 1992. Authors of plant names.1ed. Royal Botanic Gardens. Kew.

CERVI, A.C. \& DOMBROWSKI, L.T.D. 1985. Bromeliaceae de um capão de floresta primária do Centro Politécnico de Curitiba (Paraná, Brasil). Fontqueria 9:9-11.

CERVI, A.C., ACRA, L.A., RODRIGUES, L., TRAIN, S., IVACHECHEN, S.L. \& MOREIRA, A.L.O.R. 1988. Contribuição ao conhecimento das epífitas (exclusive Bromeliaceae) de uma floresta de araucária do primeiro planalto paranaense. Insula 18:75-82.

CHAUTEMS, A., 1997. New Gesneriaceae from São Paulo, Brazil. Candollea 52:159-169.

DISLICH, R. \& MANTOVANI, W. 1998. Flora de epífítas vasculares da Reserva da Cidade Universitária "Armando de Salles Oliveira" (São Paulo, Brasil). Boletim de Botânica da Universidade de São Paulo 17:61-83.

DITTRICH, V.A.O., KOZERA, C. \& SILVA, S.M. 1999. Levantamento florístico de epífitos vasculares no Parque Barigüi, Paraná, Brasil. Iheringia (Série Botânica) 52:11-22.

FISCHER, E.A. \& ARAUJO, A.C. 1995. Spatial organization of a bromeliads community in the Atlantic rainforest, South-eastern Brazil. Journal of Tropical Ecology 11:559-567.

FONTOURA, T., SYLVESTRE, L.S., VAZ, A.M.S. \& VIEIRA, C.M. 1997. Epífitas vasculares, hemiepífitas e hemiparasitas da Reserva Ecológica de Macaé de Cima. In Serra de Macaé de Cima: diversidade florística e conservação da Mata Atlântica (H.C. Lima \& R.R. Guedes-Bruni, eds.). Editora do Jardim Botânico do Rio de Janeiro, Rio de Janeiro, p.89-101.

FREIBERG, M. 1996. Spatial distribution of vascular epiphytes on three emergent canopy trees in French Guiana. Biotropica 28:345-355.

GENTRY A.H. \& DODSON, C.H. 1987. Diversity and biogeography of neotropical vascular epiphytes. Annals of the Missouri Botanical Garden 74:205-233.

IAPAR. 1978. Cartas climáticas básicas do Estado do Paraná. Instituto Agronômico do Paraná, Londrina.

INDEX KEWENSIS. 1993. Cambridge University Press, Cambridge on compact disc (versão 1.0).
KELLY, D.L. 1985. Epiphytes and climbers of a Jamaican rain forest: vertical distributions, life forms and life history. Journal of Biogeography 2:233-243.

KRESS, W.J. 1986. The systematic distribution of vascular epiphytes: an update. Selbyana 9:2-22.

LABIAK, P.H. \& PRADO, J. 1998. Pteridófitas epífitas da Reserva Volta Velha, Itapoá - Santa Catarina, Brasil. Boletim do Instituto de Botânica. 11:1-79.

LÜTTGE, U. 1989. Vascular epiphytes: setting the Scene. In Ecological Studies 79: Vascular plants as ephiphytes (U. Lüttge, ed.). Springer-Verlag, New York, p.1-12.

MADDISON, M. 1977. Vascular epiphytes: their systematic occurrence and salient features. Selbyana 2:1-13.

NADKARNI, N.M. 1986. An ecological overview and checklist of vascular epiphytes in the Monteverde cloud forest reserve, Costa Rica. Brenesia 24:55-632.

OLMSTED, I. \& JUÁREZ, M.G. 1996. Distribution and conservation of epiphytes on the Yucatán Peninsula. Selbyana 17:58-70.

PINTO, A.C, DEMATTÊ, M.E.S.P. \& PAVANI, M.C.M.D. 1995. Composição florística de epífitas (Magnoliophyta) em fragmento de floresta no município de Jaboticabal, SP, Brasil. Cientifica 22:283-289.

SEHNEM, A. 1970. Polipodiáceas. In Flora Ilustrada Catarinense (R. Reitz, ed.). Itajaí, SC, parte 1, p.1-173.

SEMA/IAP 1996. Plano de manejo da Estação Ecológica da Ilha do Mel - Paranaguá - Paraná. Programa Nacional do Meio Ambiente - Subcomponente Floresta Atlântica. Secretaria de Estado do Meio Ambiente, Curitiba.

SILVA, S.M., BRITEZ, R.M., SOUZA, W.S. \& JOLY, C.A. 1994. Fitossociologia do componente arbóreo da floresta de restinga da Ilha do Mel, Paranaguá, PR. In Anais do $3^{\circ}$ Simpósio sobre ecossistemas da costa brasileira. (S. Watanabe, coord.). Publicação ACIESP n ${ }^{\circ}$ 87, v.3 p.47-56.

STEEGE, H. \& CORNELISSEN, J.H.C. 1989. Distribution and ecology of vascular epiphytes in Lowland rain forest of Guiana. Biotropica 21:331-339.

SUDGEN, A.M. \& ROBINS, R.J. 1979. Aspects of the ecology of vascular epiphytes in Colombian cloud forests, I. distribution of the epiphytic flora. Biotropica 11:173-188.

VELOSO, H.P., RANGEL FILHO, A.L. \& LIMA, J.C. 1991. Classificação da vegetação brasileira adaptada a um sistema universal. Instituto Brasileiro de Geografia e Estatística, Departamento de Recursos Naturais e Estudos Ambientais, Rio de Janeiro.

WAECHTER, J.L. 1986. Epífitos vasculares da mata paludosa do Faxinal, Torres, Rio Grande do Sul, Brasil. Iheringia (Série Botânica) 34:39-49.

WAECHTER, J.L. 1992. O epifitismo vascular na planície costeira do Rio Grande do Sul. Tese de doutorado, Universidade Federal de São Carlos, São Carlos.

WAECHTER, J.L. 1998. Epifitismo vascular em uma floresta de restinga do Brasil Subtropical. Revista Ciência e Natura 20:43-66. 